\title{
sciendo
}

\author{
KATARZYNA WALCZAK, ANNA MAKUCH-KOCKA, JUSTYNA ZIEMIŃSKA
}

\section{Molecular mechanisms of drugs recommended in COVID-19 treatment}

\begin{abstract}
The development of an effective treatment for COVID-19 is now one of the main tasks of scientists and doctors from all over the world. The rapidly spreading SARS-CoV2 virus infection is a serious health problem among the public. Similarity of SARSCoV2 to MERS-CoV and SARS-CoV may suggest the effectiveness of COVID-19 treatment with drugs used to fight infections of previously identified Coronaviridae viruses. On the basis of gained experience and new clinical trials, the Polish Society of Epidemiologists and Infectious Diseases Physicians has created guidelines for the treatment of COVID-19. The recommendations concern primary and supportive treatment at different stages of the disease. This article provides a brief review of the molecular mechanisms of drugs currently used in Poland for the treatment of COVID-19.
\end{abstract}

Keywords: COVID-19, SARS-CoV-2 virus, remdesivir, tocilizumab, convalescent plasma, corticosteroids, anticoagulants.

DOI: $10.2478 /$ pjph-2020-0014

\section{INTRODUCTION}

Coronavirus disease 2019 (COVID-19) is an acute respiratory disease caused by the Severe acute respiratory syndrome coronavirus 2 (SARS-CoV-2 virus) of the Coronaviridae family, Coronavirinae subfamily [1,2]. The Coronavirinae subfamily is classified into four types: $\alpha$-coronaviruses, $\beta$-coronaviruses, $\gamma$-coronaviruses, and $\delta$-coronaviruses. The SARS-CoV-2, belonging to the $\beta$-coronavirus genus, is the seventh described coronavirus causing human infection $[3,4]$.

The first cases of COVID-19 among humans were reported in November 2019 in China, Wuhan Province. In January 2020, the disease began to spread rapidly throughout China and on March 11th 2020 the World Health Organization (WHO) announced the SARS-CoV-2 pandemic due to the large scale of virus epidemiology in the world $[5,6]$.

Development of an effective treatment for COVID-19 is one of the greatest challenges in the 21 st century medicine. Unfortunately, no drug has so far been found that directly affect the cause of COVID-19 - SARS-CoV-2 virus. Here, we provide a brief review on drugs currently used in the primary and adjuvant treatment of patients infected with SARS-CoV-2 based on the literature data and current treatment guidelines for COVID-19 in Poland.

\section{SARS-CoV-2 - structure and molecular mechanism of bio- logical activity}

Molecularly, SARS-CoV-2 is an enveloped virus whose genetic material is positive-stranded RNA (ssRNA $(+)$ ). The viral RNA consists of 29903 nucleotides. The coronavirus genome encodes four basic structural proteins: Spike Protein (S),
Envelope Protein (E), Membrane Protein (M), Nucleocapsid Protein $(\mathrm{N})$, helper proteins and non-structural proteins $[7,8]$.

The S Protein is a surface glycoprotein that forms the outer envelope of the virus. The $\mathrm{S}$ glycoprotein consists of the $\mathrm{S} 1$ and S2 subunits. The S1 subunit is involved in the attachment of the virus to receptors located on the surface of the host cells, whereas the S2 subunit is responsible for the binding of the viral envelope to the host cell membrane. The S2 acts as a class I viral fusion protein, mediating the fusion of the virion and cell membranes [8,9]. SARS-CoV-2 binds to angiotensin-converting enzyme II (ACE2) receptor found in lungs and other tissues in the human body [10,11]. After the SARS-CoV-2 virus S protein interacts with the ACE2 receptor on the host cell surface, the virus is fused. The enzymatic cleavage of the S protein by cathepsin $\mathrm{L}$ and Transmembrane serine protease 2 (TMPRSS2) occurs in endosomes, next, the viral RNA enters the host cells. Two polyproteins, ppla and pplab, are expressed and then cleaved by coronavirus proteases creating non-structural proteins (NSPs). NSPs enable replication of the viral genetic material and mRNA synthesis, which is a translation template for the $\mathrm{S}, \mathrm{M}, \mathrm{E}$ and $\mathrm{N}$ proteins. The mature SARS-CoV-2 virions arise in the endoplasmic reticulum-Golgi intermediate compartment (ERRGIC). The secretory vesicles transport virions to the vicinity of the cell membrane, where they are exocytosed [12]. The internalization of the virus into the host cells induces conformational changes in the $\mathrm{S}$ glycoprotein. Most likely, the conformational changes in the $\mathrm{S}$ protein make it susceptible to digestion by host cell proteolytic enzymes. This phenomenon has become the subject of research in the development of new therapeutic targets [13]. Nucleoprotein $\mathrm{N}$ participates in the replication, translation and transcription of viral RNA and is responsible 
for binding to genomic viral RNA. This protein plays an important role in shaping the virion structure by binding to other viral proteins. Envelope small membrane protein $(\mathrm{E})$ is the smallest structural protein of SARS-CoV-2 [8]. The E protein participates in the formation of virions and induction of the apoptosis process, modulates the activity of ion channels, increasing the pathogenicity of the coronavirus. The E protein forms viroporins, which are necessary for virus accumulation and release [14]. The membrane protein $(\mathrm{M})$ is the major matrix protein, playing a key role in viral morphogenesis. The $\mathrm{M}$ protein may interact with inhibitor of nuclear factor kappa-B kinase subunit $\beta$ (IKK $\beta)$. This results in the inhibition of the Nuclear Factor Kappa B (NFאB) pathway, the activation of which plays an essential role in creating the body's immune response to pathogen infection. Membrane protein $M$ enhances the proliferation of the viral pathogen by reducing the level of COX-2 [15,16].

The virus is transmitted in humans mainly by droplets or food and water [17]. COVID-19 is characterized by flu-like symptoms, including cough, fever, shortness of breath, muscle aches, headache, vomiting and diarrhea. SARS-CoV-2 may cause severe pneumonia and acute respiratory distress syndrome (ARDS) in some patients [18].

\section{Pharmacotherapy of COVID-19}

COVID-19 pharmacotherapy is based on the use of drugs with different mechanisms of action in the subsequent stages of the disease. According to recommendations of the Polish Society of Epidemiologists and Infectious Diseases Physicians, only antipyretic drugs, such as paracetamol and ibuprofen, are used in the asymptomatic or low-symptomatic stage. However, with the progress of the disease, more specific drugs are introduced into pharmacotherapy of COVID-19 [19].

\section{Remdesivir}

One of the drug used in the treatment of SARS-CoV-2 infection is Remdesivir, which is an organic chemical compound with a broad spectrum of antiviral activity. According to recommendations, it is administered in the 2nd stage of the disease to the patients with full-blown symptoms of COVID-19 [19]. As a compound from the group of nucleotide analogues, it has the ability to inhibit RNA polymerase of viruses [20,21]. Remdesivir is a prodrug of nucleoside monophosphate (NucMP) which is converted in peripheral blood mononuclear cells (PBMC) to the pharmacologically active nucleoside triphosphate (Nuc-TP). Nuc-TP, the adenosine analog, attaches to the viral RNA strand, disrupting further strand elongation, and inhibits viral replication. The negative charge of Nuc-TP initiates its accumulation in the cell. Lymphopenia is usually observed in patients diagnosed with COVID-19, suggesting that SARS-CoV-2 may infect lymphocytes. Thus, the accumulation of the drug in the PBMC may contribute to the inhibition of viral replication [22].

Remdesivir was originally intended for the treatment of Ebola virus infections, but its excellent efficacy in the treatment of MERS-CoV infection prompted its use also in COVID-19 treatment. Unfortunately, the assumptions were not confirmed because its IC50 for the SARS-CoV-2 $(0.77 \mu \mathrm{M})$ is 5-25-times higher than for the Ebola virus $(0.03-0.14 \mu \mathrm{M})$ and 2-25-times higher than for the MERS-CoV (0.03-0.34 $\mu \mathrm{M})$ [23-25]. Therefore, studies confirming the beneficial effect of the drug in inhibiting the COVID-19 are still ongoing.
It is uncertain whether the high intracellular accumulation of Nuc-TP in PBMC correlates with its clinical efficacy against SARS-CoV-2, or the distribution Nuc-TP causes high intracellular concentrations in the lungs, which are the primary target of the virus [22].

\section{Convalescent plasma}

In addition to chemotherapeutic drugs, the therapy of SARS-CoV-2 virus infection is additionally supported by the administration of convalescent plasma (CP), rich in components supporting the patient's humoral immunity. Despite limited data confirming the beneficial effect of $\mathrm{CP}$, the Food and Drug Administration (FDA) has approved its use in the treatment of patients with COVID-19 [26]. Similarly to Remdesivir, CP is administered to patients in the 2nd stage COVID-19 [19]. During apheresis, antibodies, pro- and anti-inflammatory cytokines, coagulation factors, natural antibodies, defensins, pentraxins are obtained from donors [27]. Neutralizing antibodies $(\mathrm{NAb})$ are crucial in the therapy with $\mathrm{CP}$ products. They have the ability to bind the virus and block its entry into the cell, which prevents further replication of virus. Moreover, $\mathrm{NAb}$ mediate phagocytosis of immune cells and virus elimination, therefore the effectiveness of the therapy is mainly related to their presence and titre in the CP. The IgG immune antibodies, which also bind to the virus but do not affect its ability to replicate, are equally important in COVID-19 treatment [27]. Moreover, the presence of CP anti-idiotypic antibodies and anti-inflammatory components seems very important. Anti-idiotypic antibodies originally block the autoreactive antibodies, which is crucial for the control of autoantibodies in patients with autoimmune diseases. In addition, infection is often accompanied by over-activation of the immune system due to active viral replication in macrophages. This condition is manifested by severe inflammation induced by the "cytokine storm". Previous studies revealed that cytokine storm occurs in the pathogenesis of COVID-19 and is related to the severity of the disease and poor prognosis. In the patients diagnosed with COVID-19 revealed upregulated plasma levels of IL-6, IL-2, IL-7, IL-10 and other cytokines including granulocytecolony stimulating factor, monocyte chemoattractant protein, interferon- $\gamma$ (IFN- $\gamma)$-inducible protein, macrophage inflammatory protein $1 \alpha$ and TNF- $\alpha$ [28-30]. Persistent inflammatory reaction may result in lung damage, accompanied by fibrosis and decreased organ capacity [31]. Therefore, CP rich in anti-inflammatory ingredients may help to suppress the excessive inflammatory response and accelerate recovery [27]. It is worth noting, that apart from the presence of anticoagulants in the plasma, such as antithrombin and protein $\mathrm{C}$, ultimately the plasma has a prothrombotic effect. Therefore, a special care should be taken in patients at risk of thrombosis [32].

\section{Anticoagulants}

COVID-19 is characterized with fulminant activation of coagulation and consumption of coagulation factors $[33,34]$. Extensive pneumonia can cause microthrombi formation and contribute to the frequent occurrence of thrombotic complications such as deep venous thrombosis, pulmonary embolism and arterial thrombotic complications in patients [35]. Therefore, an additional drug used in the treatment of COVID-19 is low-molecular-weight heparin (LMWH). The probable mechanism of the occurrence of thrombosis by SARS-CoV-2 is based on the induction of a cytokine storm with activation of 
leukocytes, endothelium and platelets, resulting in the activation of clotting, thrombin production and clot formation. Additionally, because SARS-CoV-2 has a high affinity for ACE2 expressed on endothelial cells, activation of these cells may initiate thrombosis. Since heparin cannot lyse an existing thrombus, the main mechanism of its anticoagulant action depends on the presence of an active antithrombin-binding sequence of pentasaccharides in the molecule (AT-III). When heparin binds to AT-III, it causes a conformational change followed by its activation. Activated antithrombin may increase its affinity for clotting factors and inactivate them (XIIa, XIa, IXa, $\mathrm{Xa}$ and IIa). Among the clotting factors, factors Xa and IIa are the most sensitive to the AT-heparin complex. In addition to its anticoagulant effect, heparin also is believed to support the anti-inflammatory and antiviral effects of other drugs [36].

\section{Tocilizumab}

Tocilizumab is a well-known IL-6 receptor antagonist, which has been widely used in the treatment of adults diagnosed with moderate and severe active rheumatoid arthritis. However, the biological activity of tocilizumab may be also crucial in the treatment of patients with COVID-19, where an important role in the initiation of cytokine storm plays pathogenic $\mathrm{T}$ cells and inflammatory monocytes secreting large amount of IL-6 [30]. Tocilizumab is recommended by the Polish Society of Epidemiologists and Infectious Diseases Physicians in the treatment of hospitalized patients in the 3rd stage of COVID-19 with respiratory failure $(\mathrm{SpO} 2<90 \%)$ [19].

Tocilizumab, a humanized monoclonal antibody, inhibits signal transduction by specifically binding to soluble IL-6 receptor (sIL-6R) and membrane-bound IL-6 receptor (mIL-6R) $[37,38]$. Taking into consideration the molecular mechanism of the biological activity of tocilizumab, this drug may be effective in preventing the consequences of "cytokine storm" in patients diagnosed with COVID-19. Moreover, tocilizumab may interact with the immune system via other mechanisms by induction of B-regulatory cells or by decrease of the expression of genes coding pro-inflammatory cytokines and chemokines [39].

Although long-term in vivo studies confirmed that tocilizumab is well-tolerated and non-toxic, it may interact with other drugs. Since IL-6 inhibits the expression of CYP1A2, CYP2C9, CYP2C19 and CYP3A4, tocilizumab may reverse CYP expression and indirectly enhance the metabolism of some drugs $[39,40]$.

\section{Corticosteroids}

The Polish Society of Epidemiologists and Infectious Diseases Physicians recommends the use of corticosteroids in the 3rd stage of COVID-19 with respiratory failure and the 4th stage of COVID-19 characterized with ARDS-acute respiratory distress syndrome [19].

Corticosteroids, synthetic steroid hormones, are used in the treatment of several diseases [41]. Dexamethasone, belonging to glucocorticoids, is commonly used in the treatment of chronic obstructive lung disease, severe allergies, autoimmune disease, asthma, skin pathologies and brain swelling [42]. Dexamethasone possesses anti-inflammatory and immunosuppressive properties and is about 25 times more active than other glucocorticoids [43]. Molecular mechanism of dexamethasone is based on the inhibition of gene expression of chemokines, cytokines and cell adhesion molecules.
Dexamethasone interacts with glucocorticoid receptor (GCR) on the cell membrane, and then is translocated as a complex to the nucleus inhibiting the expression of pro-inflammatory cytokines including IL-1, IL-2, IL-6, IL-8, TNF, IFN- $\gamma$, VEGF and prostaglandins $[44,45]$. Interestingly, dexamethasone may stimulate the expression of anti-inflammatory cytokines IL-10 and lipocortin-1. Moreover, dexamethasone may decrease the expression of AhR and IDO1 involved in the inflammation [46]. Importantly, dexamethasone acts not only at the genome level, but also at the cellular level affecting T-lymphocytes [47] and the $\mathrm{Ca}+2$ and $\mathrm{Na}+1$ movement trough the cell membrane [48].

Corticosteroid therapy is the most beneficial for patients with COVID-19 symptoms for more than 7 days and patients who required mechanical ventilation [35]. The other studies confirmed that treatment with dexamethasone decreased deaths by about $30 \%$ in mechanically ventilated patients and by $20 \%$ in patients receiving oxygen [49]. Moreover, treatment with methylprednisolone resulted in the reduced risk of death [reported by [35].

\section{CONCLUSIONS}

Despite extensive work on new drugs and COVID-19 pharmacotherapy regimens, no effective drug treatments or a vaccine have yet been developed. The basis of the COVID-19 treatment is a supportive therapy, depending on the clinical condition of the patient, and prevention of complications. COVID-19 pharmacotherapy is currently based on drugs used to fight other diseases by modifying the dosage schedules. Due to the current epidemiological situation and the lack of drugs targeting SARS-CoV-2, quick diagnosis and appropriate management of infection are important in order to limit virus transmission in the population.

\section{REFERENCES}

1. Gorbalenya AE, Baker SC, Baric RS, et al. The species Severe acute respiratory syndrome-related coronavirus: classifying 2019-nCoV and naming it SARS-CoV-2. Nat Microbiol. 2020;5:536-44

2. Shereen A, Khan S, Kazmi A, et al. COVID-19 infection: Origin, transmission, and characteristics of human coronaviruses. J Advanc Res. 2020;24:91-8

3. Ashour H, Elkhatib W, Rahman M, et al. Insights into the recent 2019 Novel Coronavirus (SARS-CoV-2) in Light of Past Human Coronavirus Outbreaks. Pathogens. 2020;9(3):186.

4. Guo Y-R, Cao Q-D, Hong Z-S, et al. The origin, transmission and clinical therapies on coronavirus disease 2019 (COVID-19) outbreak - an update on the status. Mil Med Res. 2020;7(1):11.

5. World Health Organization (WHO). Coronavirus. Geneva: WHO; 2020. [https://www.who.int/health-topics/coronavirus]

6. WHO Director-General's opening remarks at the media briefing on COVID-19. [https://www.who.int ]

7. Chan JFW, Kok KH, Zhu Z, et al. Genomic characterization of the 2019 novel human-pathogenic coronavirus isolated from a patient with atypical pneumonia after visiting Wuhan Emerg Microbes Infect. 2020;9:221-36.

8. Satarker S, Nampoothiri M. Structural proteins in Severe Acute Respiratory Syndrome Coronavirus-2. Arch Med Res. 2020;51(6):482-91.

9. Chan JFW, Kok KH, Zhu Z, et al. Genomic characterization of the 2019 novel human-pathogenic coro - navirus isolated from a patient with atypical pneumonia after visiting Wuhan. Emerg Microbes Infect. 2020;9:22136.

10. Deng SQ, Peng HJ. Characteristics of a public health responses to the coronavirus disease 2019 outbreak in China. J Clin Med. 2020;9(2):575.

11. Xu H, Zhong L, Deng J, et al. High expression of ACE2 receptor of 2019$\mathrm{nCoV}$ on the epithelial cells of oral mucosa. Int J Oral Sci. 2020;12(8). 
12. Fehr AR, Perlman S. Coronaviruses: An overview of their replication and pathogenesis. Coronaviruses. 2015;1282:1-23.

13. Jaimes JA, André NM, Chappie JS, et al. Phylogenetic analysis and structural modeling of SARS-CoV-2 Spike Protein Reveals an Evolutionary Distinct and Proteolytically-Sensitive Activation Loop. J Mol Biol. 2020;1-17.

14. Duart G, García-Murria MJ, Grau B, et al. SARS-CoV-2 envelope protein topology in eukaryotic membranes. Open Biol. 2020;10(9):200-9.

15. Fang X, Gao J, Zheng H. The Membrane Protein of SARS-CoV Suppresses NF-kB Activation. J Med Virol. 2007;79:1431-1439.

16. Alsaadi EAJ, Jones IM, Membrane binding proteins of coronaviruses. Future Virol. 2019;14:275-86.

17. Tsoi H, Li L, Chen ZS, et al. The SARS-coronavirus membrane protein induces apoptosis via interfering with PDK1PKB/Akt signalling. Biochem J. 2014;464:439-47.

18. Velavan TP, Meyer C. The Covid-19 epidemic. Tropical Med Int Health. 2020;25(3):278-80.

19. [http://www.pteilchz.org.pl/wp-content/uploads/2020/10/Aneks-2-do-Rekomendacji-PTEiLChZ-13-10-2020-pl.pdf]

20. Warren T, Jordan R, Lo M, et al. Therapeutic efficacy of the small molecule GS-5734 against Ebola virus in rhesus monkeys. Nature. 2016;531:381-5.

21. Gordon CJ, Tchesnokov EP, Feng JY, Porter DP, Götte M. The antiviral compound remdesivir potently inhibits RNA-dependent RNA polymerase from Middle East respiratory syndrome coronavirus. J Biol Chem. 2020;295(15):4773-9.

22. Sun D. Remdesivir for treatment of COVID-19: Combination of pulmonary and IV administration may offer aditional benefit [published correction appears in AAPS J. 2020;22(5):102]. AAPS J. 2020;22(4):77.

23. Wang M, Cao R, Zhang L, et al. Remdesivir and chloroquine effectively inhibit the recently emerged novel coronavirus (2019-nCoV) in vitro. Cell research. 2020;30:269-71.

24. de Wit E, Feldmann F, Cronin J, et al. Prophylactic and therapeutic remdesivir (GS-5734) treatment in the rhesus macaque model of MERS-CoV infection. Proc Natl Acad Sci USA. 2020;117:6771-6.

25. Sheahan TP, Sims AC, Leist SR, et al. Comparative therapeutic efficacy of remdesivir and combination lopinavir, ritonavir, and interferon beta against MERS-CoV. Nature Commun. 2020;11:222.

26. Sun $\mathrm{M}, \mathrm{Xu} \mathrm{Y}, \mathrm{He} \mathrm{H}$, et al. A potentially effective treatment for COVID-19: A systematic review and meta-analysis of convalescent plasma therapy in treating severe infectious disease. Int J Infect Dis. 2020;98:334-46.

27. Rojas M, Rodríguez Y, Monsalve DM, et al. Convalescent plasma in Covid-19: Possible mechanisms of action. Autoimmun Rev. 2020;19(7):102554.

28. Chen N. et al. Epidemiological and clinical characteristics of 99 cases of 2019 novel coronavirus pneumonia in Wuhan, China: A descriptive study. Lancet. 2020;395:507-13.

29. Huang C. et al. Clinical features of patients infected with 2019 novel coronavirus in Wuhan, China. Lancet. 2020;395:497-506.

30. Xu X, Han M, Li T, et al. Effective treatment of severe COVID-19 patients with tocilizumab. Proc Natl Acad Sci USA. 2020;117(20):10970-5.

31. McGonagle D, Sharif K, O'Regan A, Bridgewood C. The role of cytokines including interleukin-6 in COVID-19 induced pneumonia and macrophage activation syndrome-like disease. Autoimmun Rev. 2020;19(6):102537

32. Pathak EB. Convalescent plasma is ineffective for covid-19. BMJ. 2020;371:m4072.

33. Tang N, Li D, Wang X, Sun Z. Abnormal coagulation parameters are associated with poor prognosis in patients with novel coronavirus pneumonia J Thromb Haemost. 2020;18(4):844-7.

34. Thachil J, Tang N, Gando S, et al. ISTH interim guidance on recognition and management of coagulopathy in COVID-19. J Thromb Haemost. 2020;18(5):1023-6.

35. Wiersinga WJ, Rhodes A, Cheng AC, Peacock SJ, Prescott HC. Pathophysiology, transmission, diagnosis, and treatment of coronavirus disease 2019 (COVID-19): A review. JAMA. 2020;324(8):782-93.

36. Shi C, Tingting W, Li JP et al. Comprehensive landscape of heparin therapy for COVID-19. Carbohydr Poly. 2020;117232.

37. Davies R., Choy E., Clinical experience of IL-6 blockade in rheumatic diseases-Implications on IL-6 biology and disease pathogenesis. Semin Immunol. 2014;26:97-104.

38. Wolf J, Rose-John S, Garbers C. Interleukin-6 and its receptors: a highly regulated and dynamic system. Cytokine. 2014;70(1):11-20.

39. Scott LJ. Tocilizumab: A review in rheumatoid arthritis. (Published correction appears in Drugs). Drugs. 2017;77(17):1865-79.

40. Dhillon S. Intravenous tocilizumab: a review of its use in adults with rheumatoid arthritis. Bio Drugs. 2014;28(1):75-106.

41. Ramamoorthy S, Cidlowski JA. Corticosteroids-mechanisms of action in health and disease. Rheum Dis Clin N Am. 2016;42(1):15-31.
42. Ahmed MH, Hassan A. Dexamethasone for the treatment of coronavirus disease (COVID-19): A Review. SN Compr Clin Med. 2020;1-10.

43. Zoorob RJ, Cender D. A different look at corticosteroids. Am Fam Physician. 1998;58(2):443-50.

44. Chikanza IC. Mechanisms of corticosteroid resistance in rheumatoid arthritis: a putative role for the corticosteroid receptor beta isoform. Ann N Y Acad Sci. 2002;966:39-48.

45. Croxtall JD, Choudhury Q, Flower RJ. Glucocorticoids act within minutes to inhibit recruitment of signaling factors to activated EGF receptors through a receptor-dependent, transcription-independent mechanism. Br J Pharmacol. 2000;130:289-98.

46. Li F, Li W, Farzan M, Harrison SC. Structure of SARS coronavirus spike receptor-binding domain complexed with receptor. Science. 2005;309(5742):1864-8

47. Mitre-Aguilar IB, Cabrera-Quintero AJ, Zentella-Dehesa A. Genomic and non-genomic effects of glucocorticoids: implications for breast cancer. Int J Clin Exp Pathol. 2015;8(1):1-10.

48. Grzanka A, Misiołek M, Golusiński W, Jarząb J. Molecular mechanisms of glucocorticoids action: implications for treatment of rhinosinusitis and nasal polyposis. Eur Arch Otorhinolaryngol. 2011;268:247-53.

49. Ortolani C, Pastorello EA. Hydroxychloroquine and dexamethasone in COVID-19: who won and who lost? Clin Mol Allergy. 2020;18:17.

\section{Corresponding author}

Justyna Ziemińska

Department of Pharmacology, Medical University of Lublin

4a Chodźki St., 20-093 Lublin

E-mail: justynazieminska@umlub.pl 